\title{
EFFECT OF AUGMENTED VERBAL AND VISUAL FEEDBACK ON EFFICIENCY IN SKIING TEACHING
}

\author{
Juan Carlos Martínez¹, Pablo Jesús Gómez-López ${ }^{1}$ Pedro Femia ${ }^{2}$, \\ Daniel Mayorga-Vega ${ }^{1}$, and Jesús Viciana ${ }^{1}$ \\ ${ }^{1}$ Department of Physical Education and Sport, University of Granada, Granada, Spain \\ ${ }^{2}$ Department of Biostatistics, Faculty of Medicine, University of Granada, Granada, Spain
}

Original scientific paper

UDC: $796.926: 796.012 .26$

\begin{abstract}
:
The aims of this study were to analyse the effect of two feedback types as strategies in training ski teachers and to verify their effectiveness in the students' learning. Thirty ski teachers participated in the study (average age $=32.0 \pm 5.4$ years; average experience in ski teaching $=10.0 \pm 3$ years). The teachers were divided into two experimental groups (group I: verbal feedback; group II: visual and verbal feedback) and one control group. Fifteen teaching trials were performed by each teacher, and a subsequent instructional supervision meeting was carried out in order to analyse quality of feedbacks delivered during the trial. A total of 180 high school students participated in the study as ski learners. During the instructional supervision meeting, the teachers were guided towards a previously established theoretical model of feedback used as the evaluation criterion. The ARIMA analysis of the time series showed changes in baseline teacher behaviour (group II came closer to the model established and concentrated better than group I; both experimental groups were better than the control group). The results of the analysis of variance for the comparison of students' learning were also in the same direction: the students of group II teachers obtained better results than their peers of group I, and both experimental group's students were better than those pertaining to the control group. We recommend using the criteria of the feedback model in order to achieve better quality of teacher training in skiing.
\end{abstract}

Key words: teacher training, ski teaching, motor learning efficiency, feedback quality

\section{Introduction}

Research on effective teaching has analysed the efficacy and positive effect of feedback on specific measures of teaching and coaching, such as athletes' improvements in developing skilled performances (Lauber \& Keller, 2014; Moran, Murphy, \& Marshall, 2012), improvements in PE students' learning (Vernetta \& López-Bedoya, 1998; Viciana, Cervelló, \& Ramírez, 2007), improvements in teacher's competencies (Viciana, et al. 2013; Youdas, Krause, Hellyer, Rindflesch, \& Holiman, 2013), or in the coaches' interventions (Carpentier \& Mageau, 2014).

A variety of different feedback types could be selected in education and sport. In this research, we used feedback in two ways. Firstly, as a crucial element of teaching and learning sport skills for teachers and students, although we need to consider some characteristics of the feedback in order to achieve the greatest effectiveness (Chen, 2001); and secondly, as a strategy for training teachers, with the aim to improve their behaviour after an analysed teaching trial.
After reviewing the literature, we have selected the characteristics that feedback should have if it is to be effective and designed as a model of quality feedback (Carpentier \& Mageau, 2013). This model is based on the selected features of feedback and on the frequency with which it is given to enhance student learning in alpine skiing and other sporting disciplines. The model was discussed with experts in alpine ski teaching, who considered that it could contribute to improving quality of both the teaching intervention and student learning, thus corroborating its efficiency (Martínez, Gómez-López, Román, \& Viciana, 2007).

The model had a total of nine categories, which defined quality of feedback:

1. Specificity: predominance of prescriptive feedback, being more than $50 \%$ of the total contents (frequency) (Wrisberg, 2007).

2. Affectivity: predominance of positive feedback $(80 \%)$ over negative (frequency) (Mouratidis \& Vansteenkiste, 2010; Viciana, et al., 2007).

3. Direction: predominance of individual feedback $(80 \%)$ over group feedback (frequency) (ArcherKath, Johnson, \& Johnson, 1994). 
4. Objective: predominance of specific, technical feedback $(80 \%)$ over affective feedback (frequency) (Moreno \& Del Villar, 2004).

5. Position: assessing if teachers give feedback from a position that permits the students to see and listen in optimum conditions (yes or no) (Sáenz-López, 1997).

6. Channel: assessing if teachers supplement verbal with visual feedback (yes or no) (Crowell, Milner, Hamill, \& Davis, 2012; Eriksson, Halvorsen, \& Gullstrand, 2011).

7. Moment: feedback given immediately after a task has been completed or concurrently during long-lasting tasks (yes or no) (Eriksson, et al., 2011; Magill, 1994).

8. Comprehension: asking the students if they understood the information given as feedback (yes or no) (Lyster \& Ranta, 2000).

9. Precision: predominance of feedback focused on primary factors like the ankle, knee or waist position correction and the effects they have on the movement $(80 \%)$ over secondary factors like the head or arm position (frequency) (Wulf, Gärtner, McConnel, \& Schwarz, 2002).

The model was used in this research as the criterion of evaluation and efficiency of the feedback administered by ski teachers to their students during 15 teaching trials. In addition, to make the teachers achieve this model, we administered feedback to them regarding the results of their performance in all teaching trials, evaluating the differences between their feedback and that of the established model (Viciana, et al., 2013)

Reviewing the literature on the channel through which feedback is administered as a training strategy through an instructional supervision meeting (Holland, 2006), it was seen that both verbal and visual feedbacks were effective (Guadagnoli, Holcomb, \& Davis, 2002). Nevertheless, the visual channel exceeded and complemented the verbal channel in effectiveness, motivation and conduct reinforcement (Magill, 2010; Viciana, et al., 2013). Questions such as immediacy of feedback and technological support to show the information to the teachers were considered to increase the effectiveness of the intervention (Baca, 2004; Viciana, et al., 2013). Finally, the effectiveness of feedback for students' learning was widely stated in literature, and consequently it was taken into consideration in the construction of the model (Magill, 2010).

The main objectives of this study were: (a) to compare two strategies of ski teachers' training (by giving them visual or visual and verbal feedback regarding feedback they have administer to their students), aiming to modify teachers' behaviour and make it comparable to the model defined; (b) to verify if the model is efficient in the ski teaching setting, making the students achieve higher levels of learning in specific skills.

\section{Methods}

\section{Participants}

The sample of teachers $(n=30)$ was made up of 21 men and nine women working at the Sierra Nevada Ski Resort in Granada, Spain (average age $=32.0 \pm 5.4$ years; average years of experience in teaching ski $=10.0 \pm 3$ years). These teachers collaborated voluntarily and were selected at random from 51 teachers who originally volunteered. They were randomly assigned to one of the three groups, which were composed of 10 participants each. The groups were homogeneous, balanced by gender, experience, and the baseline results.

The sample of students treated during the study was made up of a total of 180 individuals (100 boys and 80 girls) of 12-to-16 years of age. They had no previous experience in winter sports and had a similar sports history, evaluated by means of a brief survey (they were asked if they did any physical activity, and which was its frequency and duration). All of them were participating in Physical Education classes and regular physical activity two to three days per week during their leisure time.

An observer (a working ski teacher with a degree in physical education) and a supervisor (a high school physical education teacher and active skier) also took part in the study and were blind to the objectives established. The ethical committee of the university approved this study.

\section{Measures}

Systematic observation I. A record sheet was used employing systematic live observation made by one observer trained to measure and take note of the categories established by the model. As explained in the introduction section, the categories were measured by writing down their occurrence frequencies or by a control list. This observation was carried out in each teaching trial, in order to calculate the deviation from the model criteria. Experimental group I of teachers received verbal feedback, while experimental group II was informed verbally and graphically of the deviations, obtained from comparing the model with their behaviour.

Diary: The teachers kept a diary to compare the numerical data with their thoughts during the process (Maitland \& Gervis, 2010). The teachers used diary to write down their assessment, the influence of the process on their classes, their students' progress in learning, and the effects of the feedback received on their own teaching skills. The diary was used as a complementary measurement for quantitative techniques.

Systematic observation II. The students' learning was measured by a systematic observation during a motor test executed at the end of the treatment. The test consisted of skiing down a beginner's 
track, 50 metres long and 30 metres wide, with a drop of five metres, using snowplough turns. The route had 10 gates with teaching posts 50 centimetres high in line, five metres apart, so that ten turns had to be made. The observation consisted of a control list annotating the occurrence (or not) of the following categories: a) control of velocity; b) control of direction; c) symmetry of curves; d) keeping the skis in the snowplough position; e) projection of the centre of gravity over the centre of pressure; f) skating on the inside edges of the skis; g) symmetry between the articular axes; h) lateral load shifts by flexing the ankle; i) inside ski flat and light, and j) semi-flexed arms. The students' learning level was scored from 0 to 10 .

\section{Research design}

The design of study used was a chronological series with stimulus repetition (HernándezSampieri, Fernández-Collado, \& Baptista, 2003), combining repeated intrasubject measures (10 ski teachers in each experimental group) with unifactorial intergroup comparisons (two experimental groups and one control group).

Repeated measures of the feedback categories given by the ski teachers to their high school students were recorded during each teaching trial. The measures were taken in three phases: a) baseline, with six measures per ski teacher, b) treatment, with 15 measures per teacher, and c) retention, with six measures per teacher. These are displayed in Table 1.

This research design allowed us to find out which level of feedback was more effective in enabling the teachers approaching the model and, consequently, if the students' final learning level was augmented in respect to the others groups.

\section{Variables}

The independent variable consisted of an instructional supervision meeting at which the skiing teachers were provided with knowledge of the immediate multidimensional results of the feedback they had imparted to their students in the analysed teaching trial.

Results were given in two stages: verbal (to group I) and verbal complemented with visual (to group II).

Two dependent variables were defined as:

a) Quality of feedback delivered by teachers (Dependent Variable I). This is defined as the extent to which the values of the feedback categories given by the skiing teacher approached the values established by the model.

b) Learning level attained by the students: snowplough turns (Dependent Variable II).

\section{Procedures}

After creating the sample, the observer was selected and specially trained to ensure accuracy of his recording of the two systematic observations. Only one observer intervened in the two observational processes. However, in the process of defining the categories, the observer and the main researcher of this study carried out 10 sessions before the actual data collection in order to reach a good definition of each category. In these processes the meaning of each category of observation was discussed in order to make it clearly defined for the observation. Here are the sequences of percentages of coincidences in the two observations performed [teachers' feedback: 74, 78, 84, 88, 88, 96, 89, 96, 94, 95; snowplough turns (learning): 66, 72, 78, 78, $86,84,88,89,94,94]$. Although there was only one

Table 1. Research Design Scheme used

\begin{tabular}{|c|c|c|c|c|c|c|c|c|}
\hline \multirow[b]{2}{*}{ VARIABLE } & & \multirow[b]{2}{*}{ GROUP } & \multirow{2}{*}{$\begin{array}{l}\text { Teachers/ } \\
\text { Students }\end{array}$} & \multicolumn{5}{|c|}{ MEASURES IN TIME SERIES } \\
\hline & & & & $\begin{array}{l}\text { Base } \\
\text { line }\end{array}$ & Treatment & $\begin{array}{l}\text { Students' } \\
\text { learning }\end{array}$ & $\begin{array}{c}\text { Inactive } \\
\text { period }\end{array}$ & Retention \\
\hline \multirow{3}{*}{$\begin{array}{l}\text { Independent } \\
\text { variable }\end{array}$} & 1 & group I & 10 teachers & - & $\begin{array}{c}\text { Verbal } \\
\text { feedback }\left(X_{1}\right)\end{array}$ & & - & - \\
\hline & II & group II & 10 teachers & - & $\begin{array}{l}\text { Verbal+visual } \\
\text { feedback }\left(X_{2}\right)\end{array}$ & & - & - \\
\hline & - & control group & 10 teachers & - & - & & - & - \\
\hline \multirow{6}{*}{$\begin{array}{l}\text { Dependent } \\
\text { variable }\end{array}$} & & group I & 10 teachers & $\mathrm{O}_{1} \ldots \mathrm{O}_{6}$ & $\mathrm{X}_{1} \mathrm{O}_{7} \ldots \mathrm{X}_{1} \mathrm{O}_{21}$ & & 3 weeks & $\mathrm{O}_{22} \ldots \mathrm{O}_{27}$ \\
\hline & 1 & group II & 10 teachers & $\mathrm{O}_{1} \ldots \mathrm{O}_{6}$ & $\mathrm{X}_{2} \mathrm{O}_{7} \ldots \mathrm{X}_{2} \mathrm{O}_{21}$ & & 3 weeks & $\mathrm{O}_{22} \ldots \mathrm{O}_{27}$ \\
\hline & & control group & 10 teachers & $\mathrm{O}_{1} \ldots \mathrm{O}_{6}$ & $\mathrm{O}_{7} \ldots \mathrm{O}_{21}$ & & 3 weeks & $\mathrm{O}_{22} \ldots \mathrm{O}_{27}$ \\
\hline & & group I & 60 students & level 0 & & $\mathrm{O}_{1}$ & - & - \\
\hline & II & group II & 60 students & level 0 & & $\mathrm{O}_{1}$ & - & - \\
\hline & & control group & 60 students & level 0 & & $\mathrm{O}_{1}$ & - & - \\
\hline
\end{tabular}

Note: $\mathrm{O}_{1-6}$ and $\mathrm{O}_{22-27}:$ baseline and retention measures (six observations per ski teacher in each phase); $\mathrm{X}_{1} \mathrm{O}_{7-21}:$ verbal feedback treatment with 15 measures per teacher after each teaching trial in the supervision meeting; $\mathrm{X}_{2} \mathrm{O}_{7-21}$ : verbal and visual feedback treatment with 15 measures per teacher after each teaching trial in the supervision meeting; $\mathrm{O}_{7-21}$ : 15 measures without treatment for the control group; Dependent Variable I: approximation to the model of feedback quality; Dependent Variable II: student's learning in skiing. 
observer, we also needed to train the consistency of his observation during the time within the two specific situations observed. Then, two observations were made by the observer (in the two situations: feedback and learning) one week apart, both being superior to $85 \%$ (Anguera, 1988).

The supervisor, with a bachelor degree in Physical Education, was also selected among expert ski teachers and trained for this study.

During winter the baseline, treatment, and retention data were collected and recorded. The meteorological conditions were measured throughout the process. The observation sessions took place only when the conditions of visibility and sound permitted normal acquisition of data.

Six measures per teacher were taken to establish the base line at the beginning of the process, with no indication of the nature of the task. No supervision meetings were held, and they had no knowledge of the results of their performance.

The teaching trials consisted of approximately five-ten minutes of teaching each, in which the teacher brought his/her group together (six skiing learners composed the groups), explained the task to them, demonstrated it and subsequently the students executed it. Finally, the teacher delivered feedback on the task performance to the students. The cooperation of the Ski Station and the National School of Skiing was fundamental in the process. The Ski Station facilitated the access to the chairlift situated on the ski-teaching slope in order to avoid queues, thus making possible all the trials to be performed during a journey. The head of the teachers affiliated with the National School of Skiing facilitated the organization, thus allowing the groups to frequently access the ski slope. The baseline and retention phases were registered in three days (two teaching trials each teacher a day), and the treatment was registered in five days (three teaching trials per teacher a day).

The treatment consisted of 15 measurements (15 teaching trials) for each teacher. The organisers of the Ski Station provided us with the hut for the supervision meeting close to the ski-teaching slope, which was allocated in the beginner area. The observer communicated the results of the teachers' observations by radio to the supervisor, who entered them in the computer to obtain the graphs for comparison with the model. The supervision meeting was then held in a room close to the teaching area, where verbal feedback was provided to group I, and verbal complemented with visual feedback to group II; the numerical indices were highlighted and compared with the model. Recommendations were then given to the teachers for increasing or lessening these indices to bring them into line with the model.

The visual-verbal feedback was provided showing a comparative bar graphic to the analysed teacher (see Figure 1). The teacher could watch on the screen all the categories registered of his/her delivered feedback as compared to the model. At the same time the supervisor commented the differences between his/her data and the model in each teaching trial. For instance, if the teacher delivered 10 prescriptive feedbacks to the group of ski learners regarding their fails, and only six of them were accompanied by a visual feedback, there would be a discrepancy between the bars of the graphic display indicating four feedbacks without visual demonstration. Instead of this, the experimental group I received only verbal feedback in the supervision meeting, without the graphic support of the discrepancies between their performance and

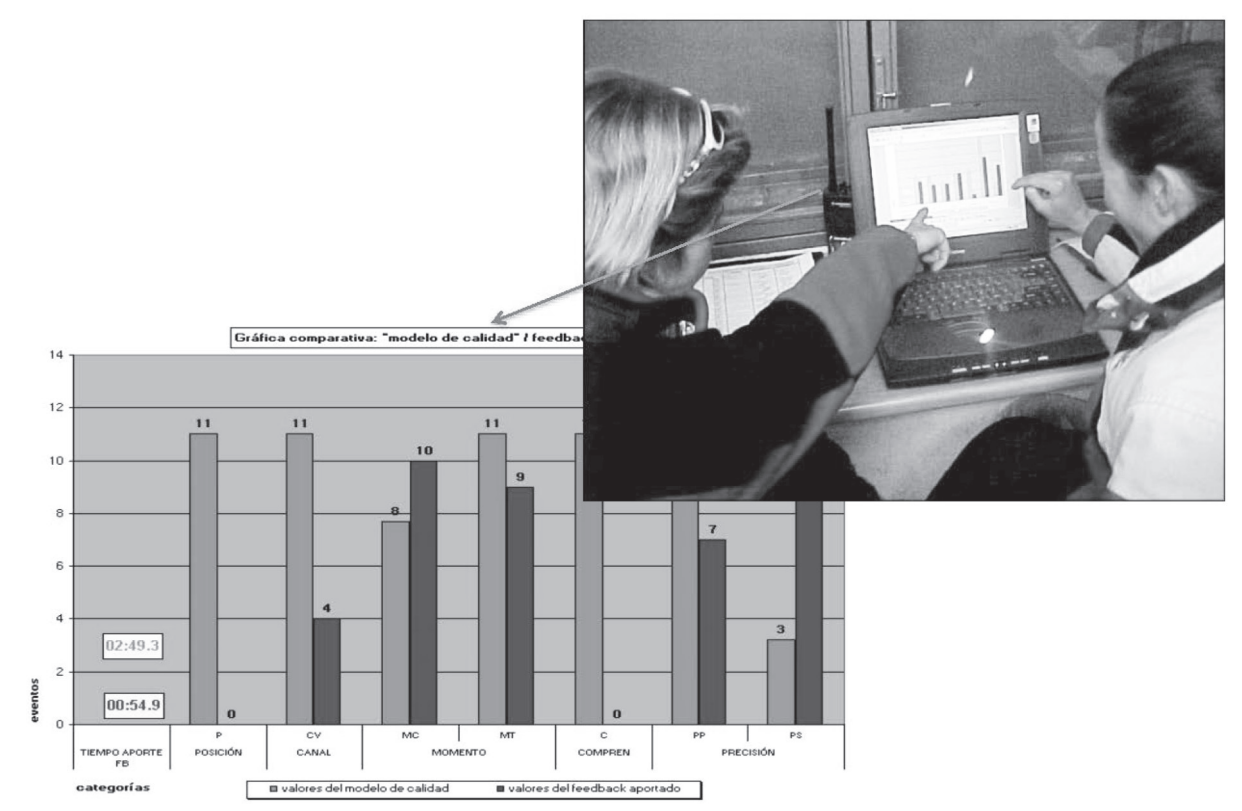

Figure 1. A supervision meeting. Visual-verbal feedback provided to teachers after their teaching trial. Comparative screen showed to teachers about their delivered feedback (dark bars) and the model (clear bars). 
the model. Suggestions like: "Prescriptive feedbacks delivered to the students regarding their fails should be accompanied by visual demonstrations" was then provided.

At the end of the treatment, the 180 students were tested to measure their level of skill acquired. An initial measurement of this variable was not necessary since all the students had the same level at the start of the treatment: none of them having skied before. Finally, the retest (six measures) was made three weeks after the treatment had been finished.

\section{Statistical analyses}

An analysis of time series (ARIMA model) was used. It offers the possibility of estimating the average levels of a series at a determined confidence level (Demetra program was used). Thus, the values registered could be observed with the reference of an estimated confidence band that enables us to assess objectively when the model has been attained and when it has not. The analysis, in all cases, has been made by focusing on both the observed and estimated values with respect to those of the model. The Demetra program used the percentage-rate of the feedback that coincided with the model in each category in order to automatically make the adjustment and validation of the ARIMA model belonging to a series of data. For instance, if only six out from 10 teacher's feedbacks were accompanied by a visual demonstration to the ski learners, the Demetra program used $60 \%$ to reflect the coincidence between teacher's performance and the model in the category of "channel". In this sense, the Demetra program reflects in its results the approximation to the model in each teaching trial analysed (negative values reflects the distance to the model by default [see Figure 2], and positive values reflect the distance to the model by excess). The Kruskal Wallis and Wilcoxon tests were used to analyse the variance in the average levels of the students' learning scores between the three groups.

\section{Results}

\section{Analysis of dependent variable I (teachers' approximation to model)}

The average levels of feedback categories and the comparison of variance with respect to the base line indicates a great and homogeneous variability between the groups. The post hoc analysis of variance test also shows that the three groups were homogeneous $(p>.05)$. In addition, the linear regression model for the base line of each teacher and group shows no tendency in the values observed of any category in the model.

The analysis of results for the treatment phase, after making adjustments to the ARIMA model, establishes the following objective criteria for the experimental groups: (a) there were significant differences between the initial prognosis and the end of the treatment for all teachers pertaining to groups I and II, thus showing the change $(\mathrm{p}<.05$ [see Table 2 for all categories]; confidence interval $=95 \%$; average values $=$ model values \pm .05 , and standard deviation $\leq .10$ were established as the criterion of adequacy for the model); and (b) the average values appeared within the confidence bands, so that it

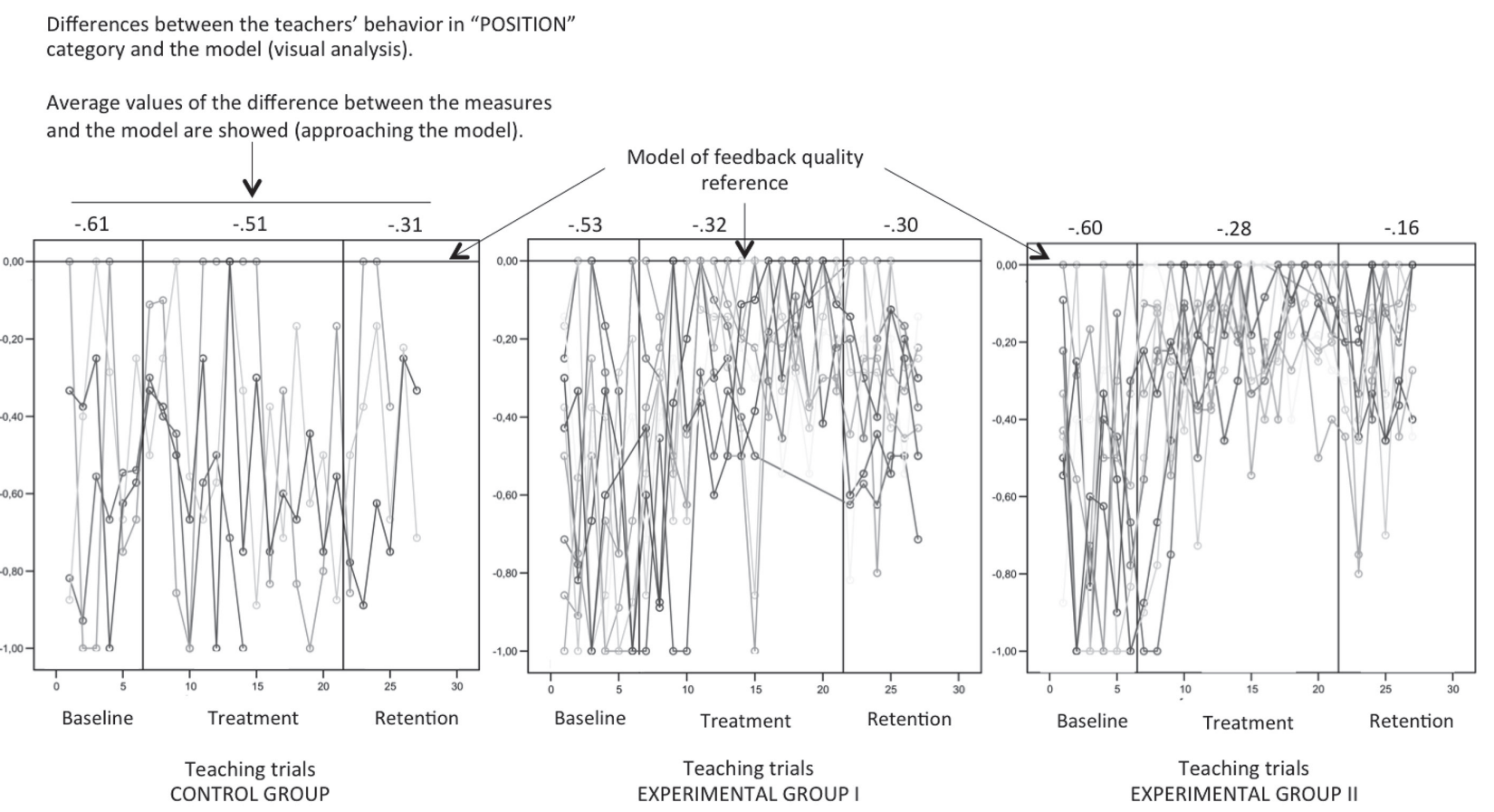

Figure 2. Visual results of the ARIMA analysis of the "position" category between the three groups. 
could be objectively stated that the model has been attained $(1,14$, and 23 teachers were within the confidence bands at the end of the treatment and the retention phases, for the control group, group I, and group II, respectively). The confidence bands of each profile also enabled us to prove the convergence to the model in its final phase (confidence interval $=95 \%$ ). As well as demonstrating a tendency to coincide with the model values, the teachers in the experimental groups, unlike those in the control group, showed a reduction of variability (group II showed more marked changes than group I), mainly at the end of the treatment phase ( $\mathrm{SD}=.12$ for group II; and $\mathrm{SD}=.31$ for group I in "position" category, see example in Figure 2).

As far as the behaviour and the development of the time series is concerned, it can be seen that the teachers in group II were more effective than those in group I and those in control group because the values of the former group at the end of the treatment phase were found to be more often within the limits of the tolerance model in all categories. For instance, in the case of the "position" category (Figure 2), the average values of the difference between the measures and the model in baseline, treatment, and retention phases were -..61, -..51, -..31 for the control group; $-.53,-.32,-.30$ for the experimental group I; and -.60, -.28, -.16 for the experimental group II, respectively (see Table 2 for all categories; in absolute values).

Teacher 5 of group II confirms this result in her diary entry: "The graphs in each meeting helped me a lot", referring to the visual feedback in the instructional supervision meeting. Teacher 1 also praised the applicability and help the experiment had given to him: "I think I'm always learning something new and it helps you improve your resources when you are working or giving classes. I'll certainly use it in the future".

Table 2 sets out the average values of the differences between the measures and model by catego- ries and by groups during the baseline, treatment, and retention phases. The ideal is that the average value should be as close as possible to the model values (value 0.00). As can be seen, the teachers in group II obtained the best points in all categories except in two cases where the teachers of experimental group I did. In the categories in which the average value of the control group teachers was, by chance, similar to those of the teachers of experimental groups, the variability was greater.

In the retention phase, the teachers of control group did not modify either their variability or their tendency. The experimental group teachers did not approach the model values as clearly as at the end of the treatment phase, but were closer than during the baseline phase. The variability of group II was smaller than that of group I, and group II approached closer to the model. The degree of retention is shown in the teachers' comments, which also confirm usefulness of the model and its applicability to ski classes. Teacher 2 in group I expressed it as follows: "I shall go on giving feedback, which I didn't do before this project, and which I have now learnt to do", or teacher 4 in the same group: "Before I learnt what ideal feedback was I had never realised importance of certain things: focus the attention on the consequences of the movement or asking the students what they thought they should do...".

Analysis of dependent variable II (students' learning)

The descriptive values show that the students of the experimental groups' teachers obtained better results than those of the control group teachers, and the students of group II teachers scored higher than the students of the teachers in group I (control group: $\mathrm{M}=5.15 \pm 2.25$; experimental group $\mathrm{I}: \mathrm{M}=6.88 \pm 1.56$; experimental group II: $\mathrm{M}=7.99 \pm 1.33$ ).

With respect to the distribution of the scores, symmetry is shown in those of the control group and there was no significance in the normality Shapiro-Wilks test. In group I and group II the

Table 2. Average values of the differences between the measures and the model during the baseline, treatment and retention phases, and significance of changes in the prognosis at the end of the treatment and retention phases

\begin{tabular}{lccccccccc}
\hline & $\begin{array}{c}\text { Prescriptive } \\
\text { feedback } \\
\text { over } \\
\text { descriptive }\end{array}$ & $\begin{array}{c}\text { Affectivity } \\
\text { (positive } \\
\text { over } \\
\text { negative) }\end{array}$ & $\begin{array}{c}\text { Direction } \\
\text { (individual } \\
\text { over group) }\end{array}$ & $\begin{array}{c}\text { Objective } \\
\text { (specific } \\
\text { over } \\
\text { affective) }\end{array}$ & $\begin{array}{c}\text { Position } \\
\text { (visibility) }\end{array}$ & $\begin{array}{c}\text { Channel } \\
\text { (verbal+ } \\
\text { visual) }\end{array}$ & $\begin{array}{c}\text { Moment } \\
\text { (concurrent } \\
\text { or just after } \\
\text { the task) }\end{array}$ & $\begin{array}{c}\text { Students' } \\
\text { comprehension } \\
\text { of feedback }\end{array}$ & $\begin{array}{c}\text { Precision } \\
\text { errors with } \\
\text { external } \\
\text { focus) }\end{array}$ \\
\hline $\begin{array}{l}\text { Group/ } \\
\text { phase }\end{array}$ & BL TR RE & BL TR RE & BL TR RE & BL TR RE & BL TR RE & BL TR RE & BL TR RE & BL TR RE & BL TR RE \\
$\begin{array}{l}\text { Control } \\
\text { group }\end{array}$ & .24 .02 .20 & .39 .29 .24 & .18 .12 .23 & .09 .16 .18 & .61 .51 .31 & .65 .73 .66 & .44 .29 .33 & .90 .98 .92 & .33 .27 .45 \\
Group I & $.19 .06 .08^{*}$ & $.30 .00 .03^{* *}$ & $.22 .08 .15^{*}$ & $.15 .11 .09^{*}$ & $.53 .32 .30^{*}$ & $.56 .28 .27^{*}$ & $.38 .07 .09^{* *}$ & $.99 .43 .39^{*}$ & $.43 .10 .12^{*}$ \\
Group II & $.20 .00 .02^{* *}$ & $.27 .01 .02^{* *} .31 .04 .09^{* *} .21 .08 .07^{* *}$ & $.60 .28 .16^{*}$ & $.58 .09 .15^{*}$ & $.42 .04 .10^{* *}$ & $.97 .13 .24^{*}$ & $.35 .06 .10^{*}$ \\
\hline
\end{tabular}

Note: BL: baseline; TR: treatment; RE: retention. All punctuations have been transformed in absolute values. Best punctuations in each category are bold.

${ }^{*} p<.05 ;{ }^{* *} p<.005$ 
distributions were very inclined to the right (accumulation of cases in the high learning levels) that induced a lack of normality ( $p=.006$ for group I and $\mathrm{p}=.001$ for group II). Afterwards, a KruskalWallis test was conducted to evaluate differences among the three groups on median change, proving it significant ( $\mathrm{p}=.002)$. The post-hoc comparisons, through the Wilcoxon test for independent samples with the Bonferroni adjustment, were also significant $(\mathrm{p}<.01$ global). In this way, it became clear that all the groups were different among themselves and that the average levels of scores were in the following direction: control group $<$ group I ( $p=.006$; effect size $\left.\mu^{2}=.41\right)$ and group I $<$ group II $(\mathrm{p}=.009$; $\mu^{2}=.36$ ).

The teachers in group II made many statements in their diaries confirming a positive effect of the treatment. Teacher 3 said: "Feedback has positively influenced learning. The motor response and the general improvement in learning are evident; quality has improved". Teacher 1 reflected: "Of course, the students have noticed my improvement in teaching thanks to feedback. I have improved a lot and this group has learned more than the others".

\section{Discussion and conclusions}

The first aim of this study was to compare two strategies of ski teachers training (by giving them only verbal or visual and verbal feedback regarding the feedback they administer to their students) aiming to modify teachers behaviour and make it closer to the model defined. The results showed that the verbal feedback complemented with visual feedback enabled the teachers in group II to come closer to attaining model than those in group I, while those in the control group did not experience that improvement. The second aim of the study was to verify whether the model was efficient in the ski teaching setting, making the students achieve higher levels of learning of specific skills. The consequence of the results regarding the first aim is reflected on the learning achieved by the students of those teachers, the students of group II teachers made the greatest progress, followed by those of group I, and then those of the control group. These results confirm that feedback is an essential variable in Physical Education teaching and sport (Eriksson, et al., 2011; Wandzilak, Bonnstetter, \& Mortensen, 1994); it is one of the basic skills in teaching alpine skiing (Ocaña, 2005), and furthermore, visual feedback complements and improves verbal feedback, as previous research has found and stated (Eriksson, et al., 2011; Guadagnoli, et al., 2002; Smith \& Loschner, 2002; Viciana, et al., 2013).

This research shows that using appropriate analyses of teachers' conduct in the teaching of alpine skiing can modify and improve the feedback they deliver, just as other authors in the Physical Education field have commented (Premuzak,
Piéron, \& Cloes, 1995). Moreover, the theoretical model of optimising efficiency in the learning of the students who received it was also verified, and it confirmed the validity of the model (Martínez, et al. 2007). The adaptation of the feedback imparted by the teachers in this study to that of the model has given higher rates of learning to their students, confirming the appropriateness of the criteria established by the categories.

In summary, the teachers in both experimental groups adapted their feedback to the criteria of efficiency marked by the theoretical model. Hence, they complemented explanations with demonstrations of errors and prescriptive information, which predominated over simple description or evaluation of the action (Vernetta \& López-Bedoya, 1998); they emphasized the predominance of positive over negative affectivity (Koka \& Hein, 2005; Viciana, et al., 2007); they directed information individually to the students in a better way (Archer-Kath, et al., 1994); their feedback was mainly centred on the specific task (Fredenburg, Lee, \& Solmon, 2001; Moreno \& Del Villar, 2004); they ensured that they gave information to the students when they were standing in the right position to make the students see and hear their instructions correctly (Magill, 2010; Sáenz-López, 1997); they delivered feedback not only communicating actions to the students verbally, but also adding visual demonstrations (Crowell, et al., 2012); they avoided delay in delivering feedback, providing it immediately after the task and even concurrently when the task permitted it, depending on its simplicity or the speed of execution (Ekblom \& Eriksson, 2012; Eriksson, et al., 2011); they ensured that all the students understood the information given, so promoting reflection on a participative and meaningful learning process (Hodges \& Franks, 2002; Lee, 1996); and finally, they focused on the primary errors in the task (usually committed with the legs or skis) and how they affect the movement rather than the secondary ones (committed with the arms and upper part of the body), paying attention mainly to the principal aspects of the action (Wulf, et al., 2002).

The main difficulties during the development of this research were the hard and changing whether conditions at the Sierra Nevada Ski resort, and the sample reduction of six students due to illness or their irregular attendance to the program, which made us exclude them from the final sample.

The main conclusions are that as the teachers came closer to attaining the model, it had greater influence on their students' learning, thus confirming its validity. Visual feedback, provided immediately using a portable computer, complements and improved verbal feedback as a strategy for skiing teachers training. Teachers attained the established model of feedback quality and maintained their learning. When the skiing teachers 
received verbal feedback complemented with visual, they gave the same type of feedback to their students, and, in turn, the students' learning was better than when they only received verbal feedback. This is an appropriate recommendation to ski teachers, mainly in pre-service training. These results represent an innovation in ski teaching because all the criteria of the feedback model had been applied to ski from the Physical Education setting and from other sports disciplines.

\section{References}

Anguera, M.T. (1988). Manual de prácticas de observación. [Observation practices manual. In Spanish.] México: Trillas.

Archer-Kath, J., Johnson, D.W., \& Johnson, R. (1994). Individual versus group feedback in cooperative groups. Jounal of Social Psychology, 134(5), 681-694.

Baca, A. (2004). Computer-science based feedback system on sports performance. International Journal of Computer Science in Sport, 2, 20-30.

Carpentier, J., \& Mageau, G.A. (2013). When change-oriented feedback enhances motivation, well-being, and performance: A look at autonomy-supportive feedback in sport. Psychology of Sport and Exercise, 14(3), 423-435.

Carpentier, J., \& Mageau, G.A. (2014). The role of coaches' passion and athletes' motivation in the prediction of changeoriented feedback quality and quantity. Psychology of Sport and Exercise, 15(4), 326-335.

Chen, D.D. (2001). Trends in augmented feedback research and tips for the practitioner. Journal of Physical Education, Recreation, and Dance, 72(1), 32-36.

Crowell, H.P., Milner, C.E., Hamill, J., \& Davis, I.S. (2012). Reducing impact loading during running with the use of real-time visual feedback. Journal of Orthopaedic \& Sports Physical Therapy, 40(4), 206-213.

Ekblom, M.M., \& Eriksson, M. (2012). Concurrent EMG feedback acutely improves strength and muscle activation. European Journal of Applied Physiology,112(5), 1899-1905.

Eriksson, M., Halvorsen, K.A., \& Gullstrand, L. (2011). Immediate effect of visual and auditory feedback to control the running mechanics of well-trained athletes. Journal of Sport Sciences, 29(3), 253-262.

Fredenburg, K.B., Lee, A.M., \& Solmon, M. (2001). The effects of augmented feedback on students' perceptions and performance. Research Quarterly for Exercise and Sport, 72(3), 232-242.

Guadagnoli, M., Holcomb, W., \& Davis, M. (2002). The efficacy of video feedback for learning the golf swing. Journal of Sports Sciences, 20, 615-622.

Hernández-Sampieri, R., Fernández-Collado, C., \& Baptista, P. (2003). Metodología de investigación. [Research methodology. In Spanish.] México: McGraw Hill.

Hodges, N.J., \& Franks, I.M. (2002). Modelling coaching practice: The role of instruction and demonstration. Journal of Sports Sciences, 20(10), 793-811.

Holland, P.E. (2006). The case for expanding standards for teacher evaluation to include an instructional supervision perspective. Journal of Personnel Evaluation in Education, 18, 67-77.

Koka, A., \& Hein, V. (2005). The effect of perceived teacher feedback on intrinsic motivation in Physical Education. International Journal of Sport Psychology, 36(2), 91-106.

Lauber, B., \& Keller, M. (2014). Improving motor performance: Selected aspects of augmented feedback on exercise and health. European Journal of Sport Science, 14(1), 36-43.

Lee, A. (1996). How and why we do research. In S. Silverman \& C. Ennis (Eds.). Student learning in physical education: Applying research to enhance instruction (pp. 9-13). Champaign, IL: Human Kinetics.

Lyster, R., \& Ranta, L. (2000). Corrective feedback and learner uptake. In J.L. Shrum \& E.W. Glisan (Eds.), Teacher's Handbook. Boston: Heinle \& Heinle.

Magill, R. (1994). The influence of augmented feedback during skill learning depends on characteristics of the skill and the learner. Quest, 46, 314-27.

Magill, R.A. (2010). Motor learning and control: Concepts and applications ( $9^{\text {th }}$ ed.). Columbus: McGraw-Hill.

Maitland, A., \& Gervis, M. (2010). Goal-setting in youth football. Are coaches missing an opportunity? Physical Education and Sport Pedagogy, 15(4), 323-343.

Martínez, J.C., Gómez-López, P.J., Román, B., \& Viciana, J. (2007). Efectividad de un modelo de calidad del feedback pedagógico en esquí alpino. [Effectiveness of a pedagogic quality feedback model in alpine skiing. In Spanish.] Revista Mexicana de Psicología, 10, 203-204.

Moran, K., Murphy, C., \& Marshall, B. (2012). The need and benefit of augmented feedback on service speed in tennis. Medicine and Science in Sport and Exercise, 44(4), 754-760.

Moreno, M.P., \& Del Villar, F. (2004). El entrenador deportivo. Manual practico para su desarrollo y formación. [The sport coach. Practical manual for the development and formation. In Spanish.] Barcelona: INDE. 
Mouratidis, A., Lens, W., \& Vansteenkiste, M. (2010). How you provide corrective feedback makes a difference: The motivating role of communicating in an autonomy-supporting way. Journal of Sport and Exercise Psychology, $32,619-637$.

Ocaña, J. (2005). Efecto de un programa de formación ininicial encaminado a la autonomía, sobre las competencias del profesor de esquí alpino y su evolución del conocimiento práctico. [Effect of a pre-service training program toward autonomy on the competencies of alpine ski teachers and the evolution of their practical knowledge. In Spanish.] (Doctoral thesis, University of Granada) Granada: University of Granada Pub.

Premuzak, J., Piéron, M., \& Cloes, M. (1995). Effectiveness of a video training programme used to improve error identification and feedback processes by physical education student teachers. International Journal of Physical Education, 32(3), 4-10.

Sáenz-López, P. (1997). La educación física y su didáctica. Manual para el profesor. [Physical Education and its didactics. Teacher's manual. In Spanish.] Sevilla: Wanceulen.

Smith, R.M., \& Loschner, C. (2002). Biomechanics feedback for rowing. Journal of Sports Sciences, $20(10), 783-791$.

Vernetta, M., \& López-Bedoya, J. (1998). Análisis de diferentes categorías del feedback en dos formas organizativas del medio gimnástico. [Analysis of different categories of feedback between two organizational systems in gymnastics. In Spanish.] Motricidad, 4, 113-130.

Viciana, J., Cervelló, E., \& Ramirez, J. (2007). Effects of manipulating positive and negative feedback on goal orientation, perceived motivational climate, satisfaction, task choice, perception of ability, and attitude to physical education lessons. Perceptual and Motor Skills, 10, 67-82.

Viciana, J., Mayorga-Vega, D., Blanco, H., Ornelas, M., Tristán, J., \& López-Walle, J. (2013). Effect of a computerized feedback on the adjustment of time in planning physical education. Procedia. Social and Behavioral Sciences, 106(10), 980-987.

Wandzilak, T., Bonnstetter, J., \& Mortensen, L.L. (1994). Examining congruence among teaching objectives, classroom behavior, and student learning: Feedback for university professors. Journal of Teaching in Physical Education, $13,60-73$.

Wrisberg, C. (2007). Sport skill instruction for coaches. Champaign, IL: Human Kinetics.

Wulf, G., Gärtner, M., McConnel, N., \& Schwarz, A. (2002). Enhancing the learning of sport skills through externalfocus feedback. Journal of Motor Behavior, 34(2), 171-182.

Youdas, J.W., Krause, D.A., Hellyer, N.J., Rindflesch, A.B., \& Holiman, J.H. (2013). Use of individual feedback during human gross anatomy course for enhancing professional behaviors in doctor of physical therapy. Anatomical Sciences Education, 6(5), 324-331.

Submitted: July 23, 2014

Accepted: January 31, 2016

Correspondence to:

Jesús Viciana, Ph.D.

Tenure Professor of the University of Granada

Department of Physical Education and Sport,

University of Granada

Ctra. Alfacar s/n, 18011, Spain

Phone: +34958246641

Fax: +34 958244369

E-mail: jviciana@ugr.es

\section{Acknowledgments}

We would like to thank Aliisa Hatten for the English revision. The fourth author is supported by a research grant from the Spanish Ministry of Education, Culture and Sport (AP2010-5905). 